\title{
Role of hysterolaparoscopy for the evaluation of primary infertility: An experience from a tertiary care hospital
}

\author{
Benudhar Pande ${ }^{1}$, Santosh Kumar Dora ${ }^{1 *}$, Sharmila Pradhan ${ }^{1}$, Bhawana Tiwary ${ }^{2}$
}

${ }^{1}$ Department of Obstetrics and Gynecology, VIMSAR, Burla, Odisha, India
${ }^{2}$ AIIMS, Patna, Bihar, India

Received: 24 May 2017

Accepted: 20 June 2017

\section{*Correspondence:}

Dr. Santosh Kumar Dora,

E-mail: santoshdora1@gmail.com

Copyright: (C) the author(s), publisher and licensee Medip Academy. This is an open-access article distributed under the terms of the Creative Commons Attribution Non-Commercial License, which permits unrestricted non-commercial use, distribution, and reproduction in any medium, provided the original work is properly cited.

\section{ABSTRACT}

Background: Infertility is one of the most common problem for which couple seeks medical attention. The main objective of the study was to assess the role of diagnostic hysterolaparoscopy in the diagnosis and treatment of primary infertility patients.

Methods: For this retrospective study, patient with the diagnosis of primary infertility were recruited. Patients admitted between the periods 2014 to 2016 were included. Pertinent data related to infertility were collected from the case records and entered in predesigned performa.

Results: Patients with primary infertility $246(82 \%)$ diagnosed to have pelvic pathology. The most common cause of infertility was ovarian $122(36.63 \%)$, Uterine $66(19.82 \%)$, tubal $84(25.22 \%)$ and unexplained infertility in 103 $(30.93 \%)$ women. Patients with PCOS $76(22.82 \%)$ and endometriosis $46(13.81 \%)$ treated with drilling and endometriotic cystectomy. In $32(9.60 \%)$ of patients hysteroscopic cannulation was done. For distal tubal blockage fimbrioplasty was performed in $38(11.41 \%)$ of women. Pelvic adhesions diagnosed in $26(7.80 \%)$ women. patients diagnosed with uterine septum $42(12.61 \%)$ required hysteroscopic septal resection. During the evaluation of infertility $70(21 \%)$ of women diagnosed to have incidental pelvic pathology treated according to pathology.

Conclusions: Hysterolaparoscopy is emerging as a valuable technique for complete assessment of female infertility and also helps in treatment according to the cause.

Keywords: Hysteroscopy, Laparoscopy, Primary infertility

\section{INTRODUCTION}

Infertility is one of the most common problem for which couple seeks medical attention. It is seen almost in 10$15 \%$ of the reproductive couple. ${ }^{1}$ Though there are various tests available for the evaluation of the patients with infertility, for the complete evaluation of pelvic pathology hysterolaparoscopy became the gold standard over the years. Ovulatory dysfunction accounts for $21 \%$ to $32 \%$, tubal factor $14 \%$ to $26 \%$, unexplained $8 \%$ to $30 \%$ and endometriosis accounts $4 \%$ to $6 \%$ of female infertility. $^{2-4}$ Hysterolaparoscopy gives detailed and magnified view of uterine, adenexal, peritoneal and other intra-abdominal pathology. Consequently, milder degree of distal fimbrial pathology, endometriosis, and pelvic adhesions can be diagnosed and treated at the same time which was missed during a routine trans vaginal ultrasonography. The main objective of the study was to assess the role of diagnostic hysterolaparoscopy in the diagnosis and treatment of primary infertility patients.

\section{METHODS}

This was a hospital based retrospective observational study. Medical records of all cases of primary infertility were retrieved and analyzed. This study was conducted 
between $1^{\text {st }}$ December 2014 to $30^{\text {th }}$ November 2016 in the Department of Obstetrics and Gynecology, VIMSAR and Samleswari hospital Burla, India. All the women with confirmed diagnosis of primary infertility admitted and managed in the above-mentioned hospital were included in this study. Infertility is defined as the failure of a couple to conceive pregnancy following 12 months of unprotected intercourse. Primary infertility patients were those who had never conceived before. Patients with secondary infertility were excluded from the study. Patients with ovulatory dysfunction, who were treated for six cycles of ovulation induction but failed to get a pregnancy, fallopian tube abnormality, unexplained infertility and patients with uterine pathology were counselled to undergo this surgery. Surgery was performed during the follicular phase of the menstrual cycle. During their first visit to hospital detail history of the patients along with general physical, systemic examinations including gynecological examination done and entered in a predesigned Performa.

\section{Statistical analysis}

All the data were entered in a SPSS-12 software and statistical analysis were calculated as per the requirement.

\section{RESULTS}

In this retrospective study, a total of 333 patients with primary infertility were recruited. The mean ages of the patients were $27.95 \pm 4.61$ year. In all the patients' diagnostic laparoscopy followed by hysteroscopy was performed except in two patients, hysteroscopy could not be performed due to cervical stenosis. The most common cause behind infertility were ovarian 122 (36.63\%), Uterine $66(19.82 \%)$, tubal $84(25.22 \%)$ and unexplained infertility in $103(30.93 \%)$ women (Table 1).

Table 1: Causes of infertility.

\begin{tabular}{|ll|}
\hline Characteristics & $\mathrm{N}=333$ (Percentage) \\
\hline Uterine fibroid & $6(1.80)$ \\
\hline Ovary & $76(22.82)$ \\
\hline PCOS & $46(13.81)$ \\
\hline Endometrioma & $122(36.63)$ \\
\hline Total & \\
\hline Tubal & $32(9.60)$ \\
\hline Proximal block & $38(11.41)$ \\
\hline Distal block & $14(4.20)$ \\
\hline Multiple block & $84(25.22)$ \\
\hline Total & $31(9.30)$ \\
\hline Unilateral block & $53(15.91)$ \\
\hline Bilateral block & $103(30.93)$ \\
\hline Unexplained & \\
\hline
\end{tabular}

When we analyse the ovarian factors causing infertility, we have found PCOS was seen in $76(22.82 \%)$ causing ovulatory dysfunction. In all patients with PCOS ovarian drilling was performed. Endometriosis was present in 46
(13.81\%) women and in all of them endometriotic cystectomy was performed. Out of 333 patients 6 $(1.80 \%)$ had intramural fibroid causing distortion of the tube and for which laparoscopic myomectomy was performed. In 331 patients, diagnostic hysteroscopy was performed (Table 2).

Table 2: Hysteroscopic findings.

\begin{tabular}{|ll|}
\hline Characteristics & N=331 (Percentage) \\
\hline Hysteroscopic findings & \\
\hline Normal findings & $273(82.47 \%)$ \\
\hline Septum & $42(12.61 \%)$ \\
\hline Synechia & $8(2.41 \%)$ \\
\hline Polyp & $4(1.20 \%)$ \\
\hline Fibroid & $4(1.20)$ \\
\hline Total & $331(100)$ \\
\hline Hysteroscopic cannulation & $20(6.04)$ \\
\hline
\end{tabular}

Most of the patients had normal hysteroscopic findings $273(82.47 \%)$. Submucus fibroid requiring hysteroscopic myomectomy was the cause of infertility in $4(1.20 \%)$ women. The commonest pathology encountered on hysteroscopy was the uterine septum 42 (12.61\%); all were treated with hysteroscopic septal resection. In 8 $(2.41 \%)$ uterine synechia was present requiring adhesiolysis. Uterine polyp was seen in 4 (1.20\%) of infertile women. With regard to tubal factor for infertility, proximal blockage, distal blockage and tube with blockage at multiple level were seen in $32(9.60 \%), 38$ (11.41) and in $14(4.20 \%)$ women respectively. In 53 (15.91\%) women presented with bilateral tubal disease and $31(9.30 \%)$ had unilateral disease.

During diagnostic laparoscopy $10(3 \%)$ women found to have paraovarian cyst requiring removal of the cyst. Four patients had asymptomatic dermoid cyst, cystectomy was performed. Two patients had serous cystadenoma confirmed postoperatively by histopathological examination. Adhesiolysis for pelvic adhesions was performed in $26(7.80 \%)$ women. Incidental findings on laparoscopy like subserous fibroid, adenomyosis, perihepatic adhesions, unicornuate uterus was diagnosed in $14(4.20 \%), 4(1.20 \%), 4(1.20 \%)$ and $6(1.80 \%)$ of women (Table 3 ).

Table 3: Incidentally diagnosed laparoscopic finding.

\begin{tabular}{|ll|}
\hline Characteristics & $\mathrm{N}=\mathbf{3 3 3}$ (Percentage) \\
\hline Paraovarian cyst & $10(3)$ \\
\hline Dermoid cyst & $4(1.20)$ \\
\hline Ovarian cyst(benign) & $2(0.6)$ \\
\hline Fibroid(incidental) & $14(4.20)$ \\
\hline Adenomyosis & $4(1.20)$ \\
\hline Pelvic adhesions & $26(7.80)$ \\
\hline Perihepatic adhesions & $4(1.20)$ \\
\hline Unicornuate uterus & $6(1.80)$ \\
\hline Total & $70(21.02)$ \\
\hline
\end{tabular}




\section{DISCUSSION}

In the modern era hysterolaparoscopy is the corner stone for the evaluation of infertile women. It facilitates the diagnosis as well as treatment of the pelvic pathology. As there is advancement in age, fertility declines progressively. In the age group between 25-29 years there is $4-8 \%$ decline in fertility. 5,6 Most of the women with infertility presented in our study were in the 25-30 years of age also reported by others. ${ }^{7,8}$ In the present study Patients with primary infertility after careful evaluation of male factors when subjected to diagnostic hysterolaparoscopy approximately $82 \%$ of patients found to have some pelvic pathology. These findings establish the role of hysterolaparoscopy in the evaluation of infertility. ${ }^{9,10}$ Ovulatory dysfunction is one of the most common cause of infertility accounting 30-40\% and Polycystic syndrome (PCOS) being the commonest finding associated with ovulatory dysfunction. ${ }^{7,11} \mathrm{We}$ report an incidence of $36.63 \%$ of patient had ovulatory dysfunction out of which PCOS constitutes 76 (22.82\%). These patients were managed by ovarian drilling which also reduces the need of gonadotropin therapy and complications associated with it. ${ }^{12}$ The next common laparoscopic finding in infertile women seen is endometriotic cyst. We report an incidence of 46 $(13.81 \%)$ women requiring endometriotic cystectomy. The incidence of endometriosis is highly variable, varies from $10 \%$ to $90 \% .^{10,13-15}$ In the developing countries due to the high incidences of tuberculosis and pelvic inflammatory disease (PID) up to $39-41 \%$ women were associated with infertility. ${ }^{16}$ PID causes damage to the fallopian tube along with pelvic adhesions, both leading to impaired tubal function and infertility. We report 32 (9.6\%) of patients had proximal block for which they have undergone hysteroscopic cannulation. Whereas 38 $(11.41 \%)$ of patients require neosalpingostomy for distal block. The most common cause behind the distal block is endometriosis, pelvic infection and prior pelvic surgery. ${ }^{17,18}$ When we have evaluated the uterine factors for infertility we have found only 10 (3\%) of patients had fibroid causing distortion of uterine cavity for which myomectomy was performed. Literature suggest there is doubtful evidence of performing myomectomy in asymptomatic patients. ${ }^{19,20}$ It can be performed laparoscopically or hysteroscopically depending on the location of fibroid. Though uterine septum mostly associated with the recurrent abortion and not with infertility we report an incidence of $42(12.61 \%)$ patients with infertility. A meta-analysis evaluated the effect of congenital uterine anomaly on reproductive outcome find that uterine septum associated with adverse pregnancy outcome. ${ }^{21}$ In all these patients hysteroscopic septal resection was performed. Due to the increase incidence of genital tuberculosis in developing country including India $8(2.41 \%)$ patients had uterine synechia for which synechia were released. These patients were evaluated for genital tuberculosis and were treated with antitubercular therapy after confirmation.
During the evaluation of infertility 70 (21\%) diagnosed to have incidental pelvic pathology those require therapeutic correction the commonest being pelvic adhesions. This is one of the advantages of laparoscopy where we can diagnose and correct at the same sittings.

\section{CONCLUSION}

The two most common factors leading to primary infertility in women are ovulatory dysfunction and tubal disease. Both the issue can be addressed surgically in carefully selected patients. In view of its increase safety it is being used as a primary diagnostic tool for the evaluation of infertility in women even in developing country. Many asymptomatic infertile patients had also some incidentally diagnosed pelvic pathology which can be treated at the same sittings. Thus, hysterolaparoscopy is emerging as a valuable technique for complete assessment of female infertility and also helps in treatment according to the cause.

\section{ACKNOWLEDGMENTS}

The Authors are grateful to all residents, faculty and staff members of Department of Obstetrics and Gynecology, VIMSAR and Sameleswari Hospital Burla for their help, support and assistance.

\section{Funding: No funding sources}

Conflict of interest: None declared

Ethical approval: The study was approved by the Institutional Ethics Committee

\section{REFERENCES}

1. Dyer SJ. International estimates on infertility prevalence and treatment seeking: potential need and demand for medical care. Hum Reprod. 2009;24(9):2379-80.

2. Maheshwari A, Hamilton M, Bhattacharya S. Effect of female age on the diagnostic categories of infertility. Hum Reprod. 2008;23:538-542.

3. Wilkes S, Chinn DJ, Murdoch A, Rubin G. Epidemiology and management of infertility: a population-based study in UK primary care. Fam Pract. 2009;26:269-74.

4. Thonneau P, Marchand S, Tallec A, Ferial ML, Ducot B, Lansac J et al. Incidence and main causes of infertility in a resident population $(1,850,000)$ of three French regions (1988-1989). Hum Reprod. 1991;6:811-6.

5. Maroulis GB. Effect of aging on fertility and pregnancy, Seminars. Reprod Endocrinol. 1991;9:165.

6. Schwartz D, Mayaux MJ. Female fecundity as a function of age: results of artificial insemination in 2193 nulliparous women with azoospermic husbands. Federation CECOS. New Engl J Med. 1982;306:404. 
7. Boricha YG, Sharma RK, Boricha BG, Mhapankar S, Chaterjee A, Narshetty J. Laparoscopy in 50 infertile couples: prospective study. Int J Med Clin Res.2011;2: 63-66.

8. Haider G, Rani S, Talpur S, Zehra N, Munir A. Laparoscopic evaluation of female infertility. J Ayub Med Coll Abbottabad. 2010;22(1):136-38.

9. Shamim S, Farooq M, Shamim R. Diagnostic Laparoscopic Findings in Infertile Patients in the Saudi Population. Pakistan J Med Health Sci. 2010;4(4):560-3.

10. Jain G, Khatuja R, Juneja A, Mehta S. Laparoscopy:As a First Line Diagnostic Tool for Infertility Evaluation. J Clin Diag Res. 2014;8(10): 01-02.

11. Hessaloniki ESHRE/ASRM-Sponsored PCOS Consensus Workshop Group. Consensus on infertility treatment related to poly-cystic ovary syndrome. Fertil Steril. 2008;89:505-22.

12. Amer SA, Banu Z, Li TC, Cooke ID. Long-term follow-up of patients with polycystic ovary syndrome after laparoscopic ovarian drilling: endocrine and ultrasonographic outcomes. Hum Reprod. 2002;17:2851-7.

13. Haney AF. Endometriosis: pathogenesis and pathophysiology. In: Wilson EA, ed. Endometriosis. New York: AR Liss, 1987;23:51-6.

14. Koninckx PR, Meuleman C, Demeyere S, Lesaffre E, Cornillie FJ. Suggestive evidence that pelvic endometriosis is a progressive disease, whereas deeply infiltrating endometriosis is associated with pelvic pain. Fertil Steril. 1991;55:759-65.

15. Bonneaua C, Chanellesa O, Siferb C, Ponceleta C. Use of laparoscopy in unexplained infertility. Eur J Obstet Gynecol Reprod Biol. 2012;163(1):57-61.
16. Goel G, Khatuja R, Radhakrishnan G, Agarwal R, Agarwal S, Kaur I. Role of newer methods of diagnosing genital tuberculosis in infertile women. Indian J Pathol Microbiol. 2013;56:155-7.

17. Kodaman PH, Arici A, Seli E. Evidence-based diagnosis and management of tubal factor infertility. Curr Opin Obstet Gynecol. 2004;16:221-9.

18. Schippert C, Bassler C, Soergel P, Hille U, Hollwitz B, Garcia-Rocha GJ. Reconstructive, organpreserving microsurgery in tubal infertility: still an alternative to invitro fertilization. Fertil Steril. 2010;93:1359-61.

19. Klatsky PC, Tran ND, Caughey AB, Fujimoto VY. Fibroids and reproductive outcomes: a systematic literature review from conception to delivery. Am J Obstet Gynecol. 2008;198:357-66.

20. Sunkara SK, Khairy M, El-Toukhy T, Khalaf Y, Coomarasamy A. The effect of intramural fibroids without uterine cavity involvement on the outcome of IVF treatment: a systematic review and metaanalysis. Hum Reprod. 2010;25:418-29.

21. Venetis CA, Papadopoulos SP, Campo R, Gordts S, Tarlatzis BC, Grimbizis GS. Clinical implications of uterine congenital uterine anomalies; a meta-analysis of comparative studies. Reprod Biomed Online. 2014;29:665-83.

Cite this article as: Pande B, Dora SK, Pradhan S, Tiwary B. Role of hysterolaparoscopy for the evaluation of primary infertility: An experience from a tertiary care hospital. Int J Reprod Contracept Obstet Gynecol 2017;6:3473-6. 